\title{
TIMING OF CRANIAL PNEUMATIZATION IN WHITE-THROATED SPARROWS ${ }^{1}$
}

\author{
R. Haven Wiley and Walter H. Piper ${ }^{2}$ \\ Department of Biology, University of North Carolina, Chapel Hill, NC 27599-3280
}

\begin{abstract}
To assess correlates of the timing of cranial pneumatization in wintering Whitethroated Sparrows (Zonotrichia albicollis), we repeatedly determined the stage of pneumatization of marked individuals in the field following autumnal migration. There were pronounced differences among individuals and among years in the timing of cranial pneumatization. Pneumatization occurred later in larger individuals, as indicated by wing length, but the timing of pneumatization was not related to dates of arrival in wintering areas nor to social dominance.
\end{abstract}

Key words: Cranium; pneumatization; White-throated Sparrow; Zonotrichia albicollis.

\section{INTRODUCTION}

The timing of cranial pneumatization in the field varies among individuals of the same species (Winkler 1979, Yunick 1979). Laboratory studies have suggested that some of this variation might result from differences in the date of hatching or nutrition (Nero 1951, Serventy et al. 1967, Biur and Thapliyal 1972, Hamel et al. 1983). If so, the timing of pneumatization might provide an indication of a young bird's age or nutritional state. Previous studies of the course of pneumatization in individual birds, however, have relied on captive subjects or on birds examined once or a few times each in the field (Nero 1951; Serventy et al. 1967; Stork 1967; Biur and Thapliyal 1972; Winkler 1972, 1979; Hamel et al. 1983; Hamel and Wagner 1990). We repeatedly examined free-living White-throated Sparrows (Zonotrichia albicollis) marked for individual identification as part of a larger study of their behavior during winter. Our study thus provided an opportunity to examine the relationships among timing of pneumatization and other attributes of individuals in the field.

When feeding during winter, White-throated Sparrows often gather in loose flocks in which they maintain stable dominance relationships. In a population in North Carolina, a bird's success in dominating opponents depends on its age and sex and on the location of its encounters in relation to the center of its range (Piper and Wiley 1991.

${ }^{1}$ Received 30 May 1991. Accepted 14 November

2 Present address: Department of Biology, Indiana University, Bloomington, IN 47405. 1989a, 1991a). Success in dominance in turn affects a bird's storage of fat, its chances of return in a subsequent year, its patterns of movement, and its ability to compete for feeding sites near cover (Schneider 1984; Piper 1990a, 1990b; Piper and Wiley 1990a, 1990b). Low-ranking birds appear not to have any compensating advantages in finding food (Wiley 1991). Consequently, success in dominance might influence a bird's cranial development by influencing its nutrition. Alternatively, success in dominance might correlate indirectly with cranial development. If age since hatching influenced dominance (Glase 1973, Rushen 1982, Arcese and Smith 1985, Kikkawa et al. 1986) and if the timing of pneumatization indicated a bird's age since hatching, then cranial development might indirectly correlate with success in dominance.

\section{METHODS}

Subjects and basic measurements. We captured White-throated Sparrows two or three times weekly from November through April 1982-1988 at Mason Farm Biological Reserve in Chapel Hill, North Carolina, but our studies of cranial pneumatization were restricted to three winters 19841987. We trapped birds in six-celled treadle traps at 17 stations $25 \mathrm{~m}$ apart along a hedgerow (Piper and Wiley 1989a). Traps were checked 2-3 times each day between 08:00 and 13:00. We took the following measurements from each bird when first captured: length of unflattened wing chord (to the nearest $0.2 \mathrm{~mm}$ ), mass (to the nearest 0.5 g), extent of subcutaneous fat in the furcula and on the abdomen (Piper and Wiley 1990a), amount of white or black in the median, lateral and su- 
perciliary stripes on the crown (Piper and Wiley, $1989 \mathrm{~b}$ ), and extent of skull pneumatization as described below. In addition, we determined each bird's sex by laparotomy (Wingfield and Farner 1976, Piper and Wiley 1991b). During the winter of 1984-1985, in order to assess the effects of laparotomy, we performed this procedure on 51 first-winter birds chosen randomly by coin tosses. Another $\mathbf{4 5}$ first-winter birds were handled in the same way except they received no laparotomy (Piper and Wiley 1991b). Birds were then released at the site of capture within two hours.

Birds subsequently recaptured during any one winter were inspected at the site of capture and promptly released. At these times, we recorded levels of fat and extent of cranial pneumatization. During the winters 1984-1987, birds originally captured with incompletely pneumatized skulls were trapped on average 13.1 times in their first winter ( $\mathrm{SD}=10.5, n=422$ ).

This species has two genetic morphs, whiteand tan-striped (Lowther 1961, Thorneycroft 1975). We could determine a bird's morph in basic plumage with an overall accuracy of $89 \%$ based on its age and sex and on measurement of its crown stripes (Piper and Wiley 1989b).

Cranial pneumatization. To inspect the cranium for pneumatization, we spread the feathers just lateral to the sagittal plane by gently blowing and, if necessary, slightly wetting them to provide a clear view of the cranium through the skin. This patch of skin could then be gently moved around with the fingers to permit inspection of the posterior, dorsal, and lateral surfaces of the cranium (see Svensson 1984, Pyle et al. 1987). The pneumatized areas, with white speckles indicating the ends of interlaminar struts, were distinctly separated from the darker unpneumatized areas. The progress of pneumatization eventually led to two, irregular, unpneumatized patches on either side of the sagittal suture, a pattern found in many emberizines (Mellencamp 1969, Winkler 1972, Yunick 1979).

Several investigators have proposed criteria for stages of pneumatization (Winkler 1972, 1979; Hamel et al. 1983). We have adopted a classification of five stages, as follows: (1) very little pneumatization; (2) at least one-quarter of the cranial surface pneumatized; (3) at least one-half of the surface pneumatized; (4) at least threequarters of the surface pneumatized (unpneumatized openings $<6 \mathrm{~mm}$ in medio-lateral diameter); and (5) completely pneumatized. With practice we could determine a bird's stage of pneumatization in the field with available light and without magnification. These scores were highly consistent between observers. On 132 occasions in 1984-1985, the same bird was captured and scored in the field twice on the same day; in $86 \%$ of cases the two scores agreed, and in the remainder, often border-line cases, they differed by only one unit.

Other measurements. Analyses of individual variation in the timing of cranial pneumatization included 14 variables. Our methods for measuring each of these variables have been described in detail previously (Piper and Wiley 1989a, $1989 \mathrm{~b}, 1991 \mathrm{~b}$ ). Determinations of wing-chord length, sex, brightness of crown stripes and morph are briefly described above; in this section we present summaries of procedures for the remaining variables.

Dominance interactions were observed at four locations along our trapline during each winter. One bird was considered dominant to another if it supplanted, attacked, or won a face-to-face fight in at least $75 \%$ of their interactions. As an index of dominance we used a bird's dominance proportion, the proportion of opponents dominated divided by the total number of opponents to which it was either dominant or subordinate. Dominance proportions were normalized with the logit transformation (Snedecor and Cochran 1967). We excluded from analyses all individuals with fewer than 10 dyadic dominance relationships.

To derive a corrected dominance proportion that compensated for the effects of location (Piper and Wiley 1989a), we added to a bird's dominance proportion an estimate of the decrease in dominance resulting from the distance between its mean trapping point and the locations of its dominance interactions (Piper 1990b). A bird's mean trapping point was the mean distance from one end of our nearly linear trap line to the locations at which it was trapped. In addition, we calculated the standard deviation of each bird's trapping locations as a measure of the extent of its range along our trap line (Piper and Wiley 1989a).

We measured a bird's subcutaneous fat at each capture by summing its scores for furcular and abdominal fat (for details see Piper and Wiley 1990a). This measure of subcutaneous fat had a simple linear relationship with body mass $\left(R^{2}=\right.$ 0.334 for linear, 0.333 for polynomial, and 0.335 
for exponential models) and thus apparently provided an interval scale of measurement for total body fat (see also Rogers 1991). An average score was obtained for each bird by taking the mean of all its measures of subcutaneous fat during January and February.

To estimate the date of arrival in the study area for each bird, we subtracted half of the mean interval between its captures from the date of its initial capture, a measure that compensated for differences in how often birds were trapped. As approximate measures of how frequently each bird visited the artificial feeding sites, we used the number of times it was trapped and the number of dyadic relationships determined for it.

Estimates of the timing of cranial pneumatization for individual birds. Although we recaptured birds repeatedly during the period when pneumatization proceeded to completion, few birds were recaptured frequently enough to allow us to determine the precise dates on which they reached a particular stage. Therefore, we employed two measures of the date on which each first-winter bird reached Stage 4 of pneumatization: (1) the first date on which the bird was actually observed in Stage 4; and (2) the average of the last date observed at Stage 3 and the first observed at Stage 4 . The date a bird was first observed in Stage 4 depended both on the date it reached this stage and on its probability of being trapped. Provided this probability remained constant within a season, the date of a bird's first capture in Stage 4 minus half the interval since its last capture in Stage 3 provides an estimate of the actual date on which it reached Stage 4. Measure (2) should thus avoid bias from individual or annual differences in rates of capture. For this measure, we included only those individuals actually observed at least once in both Stages 3 and 4, so sample sizes were smaller than for the first measure $(1984-1985, n=99,61$ respectively; $1985-1986, n=52,28 ; 1986-1987$, $\mathbf{n}=112,67)$.

Analysis of covariance applied to cranial pneumatization. To evaluate correlates of our two measures of the timing of cranial pneumatization, we used each measure as a criterion (dependent) variable in a separate analysis. As predictor (independent) variables we included all behavioral, morphological and other attributes that seemed possibly relevant: dominance proportion, corrected dominance proportion, sex, brightness of crown stripes, morph, wing-chord length, estimated arrival date, average fat score in January and February, standard deviation of trapping locations, weighted mean distance between mean trapping location and locations at which a bird was observed interacting, number of times trapped, and number of dyadic relationships.

First, we used stepwise multiple regression to eliminate variables with significance levels greater than 0.15 (Systat, Inc., Evanston, Illinois; see Piper and Wiley 1989a). Next, we tested all interactions among the selected variables for significance. Finally, since one of the final predictor variables (year) had three levels, we examined the resulting model with an analysis of covariance. We took $\alpha=0.004$ in accordance with the Bonferroni method $(0.05 / 14$ variables; Keppel, 1982) to adjust for the large number of variables considered.

To assess the influence of laparotomy on cranial development in our sample of birds randomly assigned to categories of treatment and control, we used an analysis of covariance with the date first observed in Stage 4 as the dependent variable and with arrival date and laparotomy as categorical independent variables and wing length as a continuous independent covariate.

\section{RESULTS}

Laparotomy and cranial development. Subjects randomly assigned to receive laparotomies in 1984-1985 did not differ from the controls in dates they were first observed in Stage 4 of cranial development (mean date $87.4 \pm 18.9$ days after October 1 for birds subjected to laparotomy, 88.7 \pm 17.8 days for birds not so treated, $F=0.089$, $n=72, P>0.5$ ). Thus we conclude that laparotomy had no effect on the progress of pneumatization in our study. In general, laparotomy had little effect on these subjects (Piper and Wiley $1991 \mathrm{~b}$ ); we do not mention it further here.

Annual variation in cranial development. Known first-winter White-throated Sparrows varied considerably in the dates on which they reached different stages of cranial pneumatization. In addition, there was considerable variation in the course of pneumatization in this population from year to year (Fig. 1). In 1984-1985, $14.5 \%$ of birds had completed pneumatization by 29 December. In 1986-1987, 40\% had completed pneumatization by that date. In the three years of this study, $50 \%$ of birds had completed cranial pneumatization by 28 January, 29 De- 


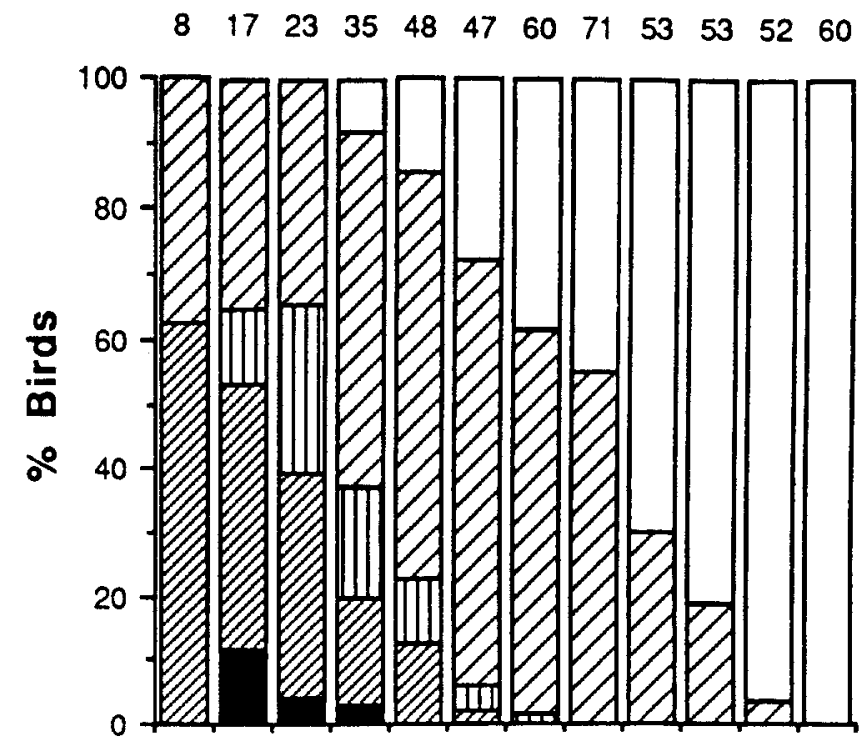

1984-85

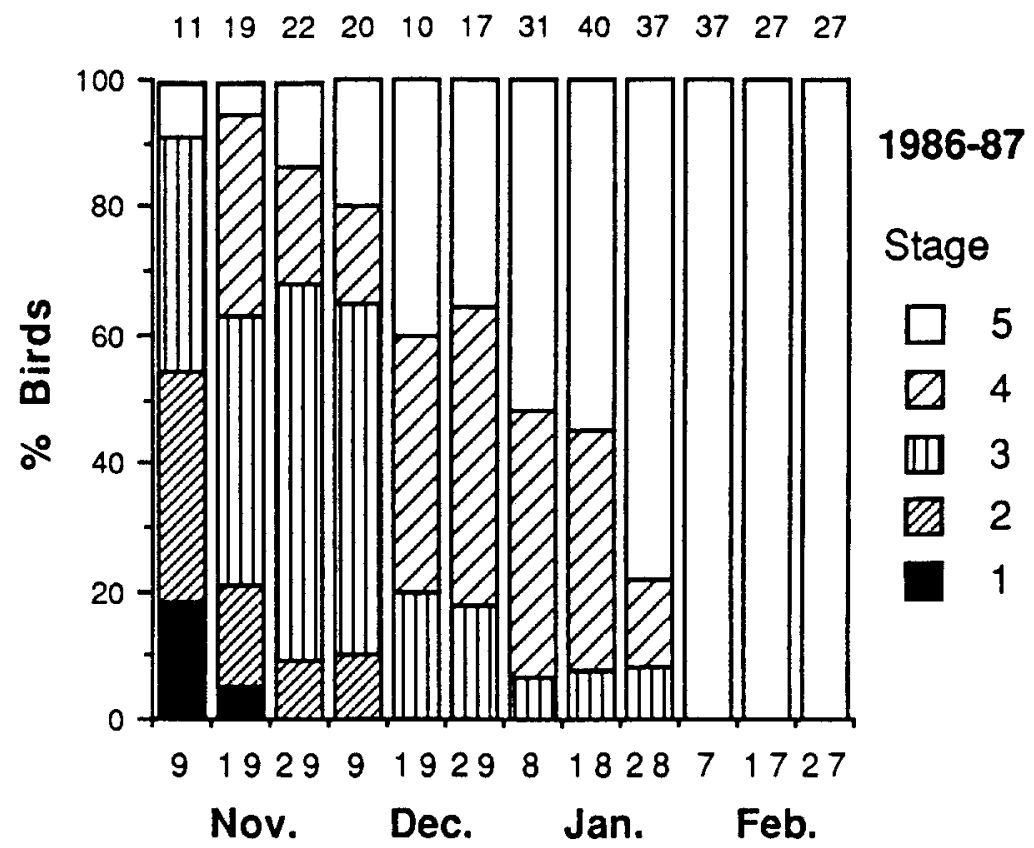

FIGURE 1. The distributions of the stages of cranial pneumatization in first-winter White-throated Sparrows at intervals of 10 days in 1984-1985 and 1986-1987. Number above each column indicates $n$; these data include only those birds known to have had a particular stage of pneumatization on the date indicated.

cember, and 8 January, respectively, and 10\% had completed pneumatization by 19 December, 29 November, and 9 November. Pneumatization is completed in virtually all birds during the first winter. Over five years, among more than 300 banded birds returning to our study area for their second winter, only one had incomplete pneumatization (unilateral, $<2 \mathrm{~mm}$ diameter).

Individual differences in cranial development. In examining our first measure of the timing of pneumatization, the earliest date on which a bird was actually observed in Stage 4, we identified 
TABLE 1. Analysis of covariance of variables affecting the first date on which a bird was observed in Stage 4 of cranial pneumatization.

\begin{tabular}{lrrrr}
\hline \hline \multicolumn{1}{c}{ Variable } & df & \multicolumn{1}{c}{$\begin{array}{c}\text { Mean } \\
\text { square }\end{array}$} & \multicolumn{1}{c}{$\boldsymbol{F}$} & \multicolumn{1}{c}{$\boldsymbol{P}$} \\
\hline Arrival date & 1 & $7,702.0$ & 24.6 & $<0.001$ \\
Year & 2 & $6,299.5$ & 20.1 & $<0.001$ \\
Wing length & 1 & $3,114.2$ & 9.9 & 0.002 \\
Error & 166 & 313.1 & & \\
\hline
\end{tabular}

$R^{2}=0.324 ; n=171$.

three variables related to pneumatization: arrival date, year, and length of wing chord (Table 1, Fig. 2). None of the first-order interactions of predictor variables was significant (for the closest case, the interaction between wing chord and year, $P=0.044)$. The association of sex, a correlate of wing-chord length, with our first measure of pneumatization was much weaker $(P=0.048)$. Because the positive regression of this measure on length of wing chord remained significant within each sex separately, we concluded that our first measure of the timing of pneumatization was primarily related to wing length rather than sex.

In analyzing our second measure of pneumatization, the estimated date on which a bird reached Stage 4 , we found that arrival date and year were again related to the timing of pneumatization (Table 2). The effect of wing length

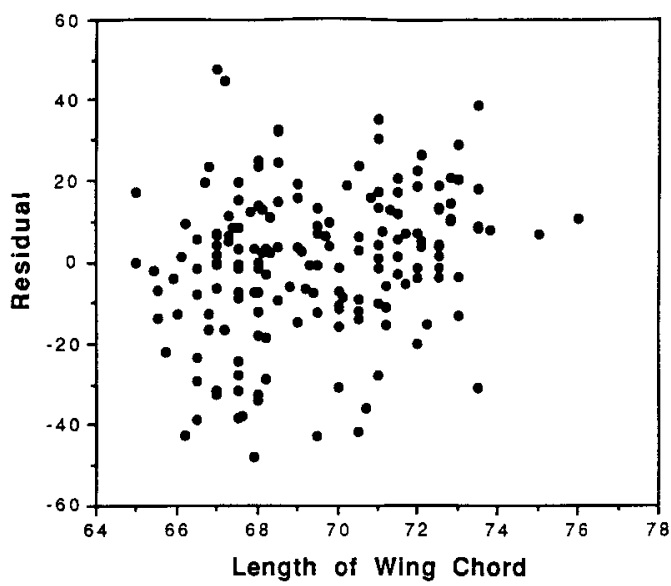

FIGURE 2. The relationship between the first date a bird was observed in Stage 4 of cranial development (residuals from an analysis of covariance with year and date of arrival as predictor variables) and the length of its wing chord. in this analysis failed to reach significance. These three variables together explained slightly more of the total variance in our second measure of pneumatization than in our first (Table 2).

The negative correlation of arrival date with the timing of cranial pneumatization was a result of the constraint that no bird could be observed in Stage 4 of pneumatization before it arrived. Later arrivals included some birds that had already reached Stage 4 , a situation that biased observations of cranial development in these birds. Further examination of the data from 1984-1985 showed that birds arriving earlier took longer to reach Stage 4 than those arriving later (Fig. 3). If pneumatization proceeded independently of migration, we would expect the slope of this relationship to equal -1.0 . The observed value, -0.92 , probably deviates from -1.0 because birds arriving late were more likely to have completed pneumatization before arrival. Thus our results provided no evidence that the timing of pneumatization was influenced by migration. Inclusion of estimated arrival dates in our analyses served primarily to control for this nuisance variable.

Dominance and cranial development. Neither dominance proportion nor corrected dominance proportion was significantly associated with pneumatization in our analyses. To determine whether the timing of pneumatization might affect the previously published results for the predictors of dominance (Piper and Wiley 1989a), we tested a model with dominance proportion as the criterion variable and the following as predictor variables: sex, location (weighted mean distance between a bird's mean trapping location and sites at which we observed its dominance interactions), and date first observed with Stage 4 of pneumatization. This model thus included those variables previously found to have significant associations with dominance proportion,

TABLE 2. Analysis of covariance of variables affecting the first date on which a bird was estimated to have reached Stage 4 of cranial pneumatization.

\begin{tabular}{lrrrr}
\hline \multicolumn{1}{c}{ Variable } & df & \multicolumn{1}{c}{ Mean } \\
square & \multicolumn{1}{c}{$F$} & \multicolumn{1}{c}{$\boldsymbol{P}$} \\
\hline Arrival date & 1 & $6,812.5$ & 28.2 & $<0.001$ \\
Year & 2 & $2,580.9$ & 10.7 & $<0.001$ \\
Wing length & 1 & 987.5 & 4.1 & 0.046 \\
Error & 110 & 241.4 & & \\
\hline
\end{tabular}

$R^{2}=0.354 ; n=115$. 


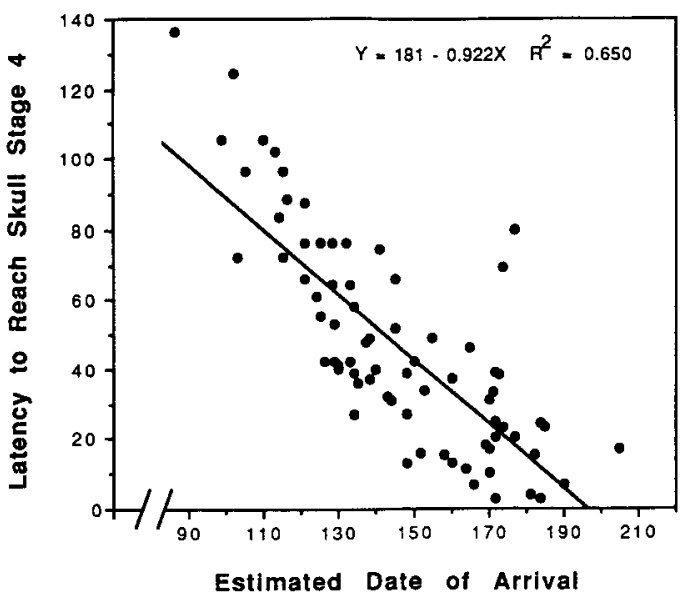

FIGURE 3. The relationship between a bird's estimated date of arrival $(100=$ October 1$)$ and time after arrival until it was first observed in Stage 4 of cranial development.

with the exception of age, since only first-winter birds were included here. Location and sex, but not the timing of pneumatization, were significantly related to dominance (Table 3 ).

\section{DISCUSSION}

Comparisons with other studies. In this study, as in previous studies of White-throated Sparrows (Mellencamp 1969) and other emberizines (Winkler 1972, 1979), pneumatization occurred primarily after autumnal migration and continued in many individuals into January and February. With only rare exceptions, birds completed pneumatization well before the partial prealternate molt and vernal migration.

The present study differed from previous ones in following large samples of marked individuals in the field. When individuals are examined only once, there is often no way to distinguish firstyear birds that have completed cranial development from older birds. As a consequence, the presentation of field data on seasonal changes in the proportions of birds with different stages of pneumatization(Winkler 1972, 1979) confounds the seasonal development of individual birds with seasonal changes in age ratios. This problem is not encountered when marked birds are examined repeatedly.

Annual and individual variation. The analyses of covariance for our two measures of the timing of pneumatization (date first observed in Stage 4 and estimated date of reaching Stage 4) both showed significant effects of year. Wing length had a significant influence on the first measure but not the second. This lower level of significance for wing length in the second analysis in comparison to the first probably resulted from the smaller sample size.

Bias caused by trapping frequency did not produce the significant differences among years in our first measure of cranial development. The year in which we trapped birds most intensively for examination of their skulls, 1984-1985, was the year with the latest cranial development, not the earliest as expected from a trapping-frequency bias. Also our second measure of cranial development, which should be free from trappingfrequency bias, showed significant differences among years. Thus we conclude that there are real differences between years in the timing of cranial development. The causes of these differences remain unknown but might include annual differences in nutrition or phenology of hatching. Annual variation in timing of pneumatization makes it necessary to be cautious in determining age by cranial pneumatization after November.

Bias from differences in trapping frequency also cannot explain the significant effect of wing length on our first measure of cranial development, since wing length did not correlate with frequency of capture. Our analyses provided no evidence that this influence of wing length on the timing of cranial development resulted either from nutritional deficiencies associated with large size or from indirect effects of sex. The initial stepwise

TABLE 3. Correlates of dominance in white-throated sparrows (partial correlation coefficients from multiple regression).

\begin{tabular}{lrr}
\hline \multicolumn{1}{c}{ Variable } & Coefficient & $P$ \\
\hline Distance from mean trapping point & -0.35 & $<0.001$ \\
Sex & 0.31 & 0.001 \\
Date first observed with pneumatization Stage 4 & -0.08 & $>0.3$ \\
\hline
\end{tabular}

$R^{2}=0.212 ; n=113$. 
multiple regressions provided no evidence that pneumatization was associated with use of artificial sources of food, our one measure of feeding. However, use of these sources only became frequent during December and January, after most pneumatization had already occurred. The stepwise multiple regressions, in addition, eliminated sex as a significant predictor of cranial development, and bivariate analyses showed that the timing of pneumatization correlated with wing length within each sex separately. Thus wing length appears to have a weak but unexplained influence on cranial development in this population.

Cranial development, hatching date and dominance. We found no indication that timing of pneumatization correlated with a bird's dominance in its first winter. Apparently, either hatching date had little effect on dominance in a Whitethroated Sparrow's first winter, or hatching date had little relation to the timing of pneumatization, or both. The relationship between age and cranial development might also vary over the latitudes encompassed by the breeding range (Winkler 1979). Consequently, for White-throated Sparrows, the relationships among hatching date, dominance, and timing of pneumatization remain uncertain.

Previous studies that have reported relationships between dominance and age during the first year of life have all involved permanently resident species (Arcese and Smith 1985, Kikkawa et al. 1986). Our failure to confirm a relationship between dominance and timing of pneumatization leaves open the question of whether or not dominance during winter is influenced by hatching date in migratory species.

\section{ACKNOWLEDGMENTS}

This research was supported in part by grants from the Frank M. Chapman Memorial Fund and Sigma Xi. It is a contribution from the Behavioral Research Station in the Mason Farm Biological Reserve, North Carolina Botanical Garden.

\section{LITERATURE CITED}

ArCese, P., AND J.N.M. SMith. 1985. Phenotypic correlates and ecological consequences of dominance in Song Sparrows. J. Anim. Ecol. 54:817830.

Biur, K., AND J. P. Thapliyal. 1972. Cranial pneumatisation in the Indian weaver bird Ploceus philippinus. Condor 74:198-200.

Glase, J. C. 1973. Ecology of social organization in the Black-capped Chickadee. Living Bird 12:235267.

Hamel, P. B., J. L. Beacham, AND A. E. Ross. 1983. A laboratory study of cranial pneumatization in Indigo Buntings. J. Field Ornithol. 54:58-66.

HAMEL, P. B., AND S. J. WAGNER. 1990. Laboratory and field investigation of skull pneumatization in Song and Swamp Sparrows. J. Field Ornithol. 61: 34-40.

KePrel, G. 1982. Design and analysis. Prentice-Hall, Englewood Cliffs, NJ.

Kikkawa, J., J.N.M. Smith, R. Prys-Jones, P. Fisk, AND C. CATterall. 1986. Determinants of social dominance and inheritance of agonistic behavior in an island population of silvereyes, Zosterops lateralis. Behav. Ecol. Sociobiol. 19:165-169.

Lowther, J. K. 1961. Polymorphism in the Whitethroated Sparrow, Zonotrichia albicollis. Can. J. Zool. 39:281-292.

MellenCAMP, W. R. 1969. Skull ossification in the White-throated Sparrow. Eastern Bird-Banding News 32:109-111.

Nero, R. W. 1951. Pattern and rate of cranial ossification in the House Sparrow. Wilson Bull. 63: 84-88.

PIPER, W. H. 1990a. Exposure to predators and access to food in wintering White-throated Sparrows $\mathrm{Zo}$ notrichia albicollis. Behaviour 112:284-294.

PIPER, W. H. 1990b. Site-tenacity and dominance in wintering White-throated Sparrows Zonotrichia albicollis (Passeriformes: Emberizidae). Ethology 85:114-122.

Piper, W. H., ANd R. H. Wiley. 1989a. Correlates of dominance in wintering White-throated Sparrows: age, sex and location. Anim. Behav. 37:298310.

Piper, W. H., AND R. H. Wiley. 1989b. Distinguishing morphs of the White-throated Sparrow in basic plumage. J. Field Ornithol. 60:73-83.

PIPER, W. H., AND R. H. WILEY. 1990a. The relationship between social dominance, subcutaneous fat and annual survival in wintering White-throated Sparrows (Zonotrichia albicollis). Behav. Ecol. Sociobiol. 26:201-208.

Piper, W. H., AND R. H. Wiley. 1990b. Correlates of range size in wintering White-throated Sparrows (Zonotrichia albicollis). Anim. Behav. 40: 545-552.

PIPER, W. H., AND R. H. WILEY. 1991a. Errata: correlates of dominance in White-throated Sparrows. Anim. Behav. 42:339.

Piper, W. H., AND R. H. Wiley. 1991b. Effects of laparotomies on wintering White-throated Sparrows and the usefulness of wing chord as a criterion for sexing. J. Field Orithol. 62:40-45.

Pyle, P., S. Howell, R. Yunick, and D. De Sante. 1987. Identification guide to North American passerines. Slate Creek Press, Bolinas, CA.

ROGERS, C. M. 1991. An evaluation of the method of estimating body fat in birds by quantifying visible subcutaneous fat. J. Field Ornithol. 62:349356.

Rushen, J. 1982. The peck-orders of chickens: how do they develop and why are they linear? Anim. Behav. 30:1129-1137. 
SCHNeider, K. J. 1984. Dominance, predation, and optimal foraging in the White-throated Sparrow. Ecology 65:1820-1827.

Serventy, D. L., C. A. Nicholls, and D. S. Farner. 1967. Pneumatization of the cranium of the Zebra Finch Taeniopygia castanotis. Ibis 109:570578.

SNedecor, G. W., and W. G. Cochran. 1967. Statistical methods. Sixth ed. Iowa State Univ. Press, Ames, IA.

Stork, H.-J. 1967. Zur Pneumatisation der Schädeldecke bei juvenilen Drosseln. Zool. Anz. 179:340354.

SvEnSSON, L. 1984. Identification guide to European passerines. Third ed. Naturhist. Riksmuseet, Stockholm.

THORNEYCROFT, H. B. 1975. A cytogenetic study of the White-throated Sparrow, Zonotrichia albicollis. Evolution 29:611-621.

WILEY, R. H. 1991. Both high- and low-ranking Whitethroated Sparrows find novel locations of food. Auk 108:8-15.

WingField, J. C., AND D. S. Farner. 1976. Avian endocrinology: field investigations and methods. Condor 78:570-573.

WINKLER, R. 1972. Zum Verlauf der Schädelpneumatisation bei Singvögeln. Ornithol. Beob. 69:287296.

WINKLER, R. 1979. Zur Pneumatisation des Schädeldachs der Vögel. Ornithol. Beob. 76:49-118.

YUNICK, R. P. 1979. Variation in skull pneumatization patterns of certain passerines. N. Am. Bird Bander 4:145-147. 